\title{
Does Classroom Characteristic Truly Stimulate Learning Motivation and Performance? Reporting from Malaysian Undergraduates' Perception
}

\author{
Siti Fardaniah Abdul Aziz ${ }^{1}$, Jamiah Manap ${ }^{1}$, Arena Che Kasim ${ }^{1}$, Mohd. Nasir Selamat ${ }^{1}$, Noordeyana Tambi $^{1}$ \& \\ Fazilah Idris $^{2}$ \\ ${ }^{1}$ Faculty of Social Sciences \& Humanities, Universiti Kebangsaan Malaysia, Malaysia \\ ${ }^{2}$ Centre for Citra University, Universiti Kebangsaan Malaysia, Malaysia \\ Correspondence: Siti Fardaniah Abdul Aziz, Faculty of Social Sciences \& Humanities, Universiti Kebangsaan \\ Malaysia, Malaysia. E-mail: daniah@ukm.edu.my
}

Received: December 9, 2014 Accepted: February 10, 2015 Online Published: May 15, 2015

doi:10.5539/ass.v11n15p84 URL: http://dx.doi.org/10.5539/ass.v11n15p84

\begin{abstract}
Some researchers find that learning intervention can stimulate learning motivation and performance through classroom characteristic. Ironically, research assessing classroom characteristic that can be used as potential learning intervention have received little attention especially among Malaysian undergraduates. Hence, the aim of this study is to determine the mediation effect of motivation to learn on the relationship between classroom characteristic and students' grade performance. A number of 173 undergraduate students in a large Malaysian's public university were taken as sample; data were analysed using SPSS and AMOS. Findings indicated that teaching method, followed by lecturer quality, and classroom management were significantly correlated with students' motivation to learn and performance; wherein, motivation to learn fully mediated the relationship between the classroom characteristics and students' grade. This has verified that classroom characteristic truly stimulate learning motivation and performance; therefore, it can be used as potential learning intervention.
\end{abstract}

Keywords: Malaysian undergraduates, motivation to learn, academic performance, classroom characteristics, potential intervention

\section{Introduction}

Learning process for undergraduate students has been replaced by andragogy from pedagogy approach; in which, andragogy approach of learning relies on the person's self-concept, experience, readiness to learn, orientation to learn, and motivation to learn (Knowles, 1980). Hence, students choose what they want to learn, learn using their experience, learn when they are ready, learn something that can be used for life, and learn only if they are motivated to learn. Clearly, undergraduate students are not forced to learn, but will learn if they are motivated to learn (Coleman, 2006).

According to Taylor-Sims (2011), several factors can affect students' motivation including parents' characteristic, student's ability and characteristics, and classroom characteristic. Since parents and student's characteristics cannot be controlled; it can be seen that classroom characteristic is the most important factor to stimulate students' motivation. Meanwhile, Griffin et al. (2013) find that students' motivation had a large effect on academic performance, in which it explains 50\% variants in academic achievement (GPA). Hence, lecturer should use appropriate classroom characteristic as an intervention to stimulate motivation to learn and subsequently increase the students' performance.

Nonetheless, studies about classroom characteristics that can be used as learning intervention to stimulate motivation to learn and student performance have received little attention especially in Malaysia (Normaliza, 2005; Noordin et al., 2010). Therefore, the purpose of this study is to assess the mediation effect of motivation to learn on the relationships between classroom characteristic and students' grade in order to suggest potential intervention for teaching and learning $(T \& L)$.

\section{Literature Review}

Various efforts was taken by teachers/lecturers to improve students' performance in classroom setting either in lower or higher educational institutions. The system of T\&L in higher educational institutions is different from 
those practices in lower educational institutions because it considers the differentiation of pedagogy and andragogy approach (Taylor-Sims, 2011). Ironically, prior researchers find that the same factors were indicated to influence students' performance either in lower or higher educational institutions. These include the individual, parent, and classroom characteristics (Montgomery, 1998; Taylor-Sims, 2011). However, the classroom characteristic should be the most easier to be manipulated because other characteristics cannot be controlled by the teachers/lecturers (Siti Fardaniah \& Shamsuddin, 2011). Interestingly, recent studies have shown that learning intervention can be maximized if students are motivated to learn because it can affect students' performance to a large effect size (Griffin et al., 2013). Hence, it is important to determine the effect of motivation to learn as a mediator on the relationship between classroom characteristic and students' performance.

\subsection{Evaluation of Academic Performance for Undergraduate Students}

The evaluation of students' performance for undergraduate students is different from those used in schools because it considers the transition of students from pedagogy to andragogy of learning (KPM, 2014). In Malaysia, the evaluation of school students is more on a paper and pencil test. For example, the UPSR test (Primary School Assessment Examination) for primary school students, the PMR test (Lower Secondary School Assessment Examination) for the lower secondary school students, and SPM test (Malaysian Educational Certificate) for the higher secondary school students. These examinations are used to determine the students' performance in school. However, in higher educational institutions, the evaluation for undergraduate students is based on CGPA (Cumulative Grade Point Average).

Cumulative Grade Point Average is calculated based on the total number of subjects taken by students in higher educational institutions (JPT, 2014). Interestingly the evaluation of students is not based on paper and pencil test solely, but it depends on the subject that taken by students. Some subjects evaluate the students' performance by dividing it into certain percentage of paper and pencil test, quiz, academic writing assignment, activity assignment, individual assignment, discussion, lab practice, group assignment, etc. Depends on the lecturer, some time students are not evaluated using a paper and pencil test at all. The evaluation for students are informed in the first class based on the course framework/planning that usually referred to as "pro-forma". These evaluations contribute percentage to determine the students' grade that finally translated into CGPA. For example, $80 \%$ achieved marks is an A grade or 4 point average. If a student took only 3 subjects in a semester with grade A for each subject, the CGPA is 4.0. Therefore, this is how the undergraduate students are evaluated in higher educational institutions.

There are many techniques to evaluate the undergraduate students' performance; however, at the end, it will depend on the students' grade for each subject. Therefore, the grade that student achieves in a subject should be used to determine student's performance for the undergraduates.

\subsection{Factors Related to Undergraduate Students' Academic Performance}

Montgomery (1998) and Taylor-Sims (2011) argue that there are three major factors that can affect students' academic performance; these include the individual, parents, and classroom characteristics. Meanwhile, Debnath (2005) develops a model of college students' motivation to explain on how variety factors including the macro environment (school environment and system, family, state, nation), micro environment (classroom environment), students' factors (individual factor), and students' motivation to learn are related to students' academic performance (see Figure 1). The model is consistent with Fazal, Nabi and Abdul (2010) findings among school students in English subject that also demonstrate three major factor for students' academic motivation and achievement including individual (e.g., low self-esteem, fear of laughter by students), parents (e.g., no encouragement from parents), and classroom characteristic (e.g., rapid pace of the lesson, fear that teacher would correct mistakes immediately in front of the whole class, no use of modern technological aids in teaching English, and teachers anger over a wrong answer).

Interestingly, most of researchers find that individual factor, or specifically students' motivation was the most influential factor for academic performance. For example, Shea (2006) tested whether individual and family factors are related to achievement among school students and finds that the combination of both factors will determine the academic achievement. However, Shea (2006) finds that the individual factor is more influential than the family factor; this is consistent with Montgomery's (1998) findings. Meanwhile, students' motivation to learn as individual factor was found to be the most influential factor for academic performance (Masahiro-Yoshida et al., 2008; Crumpton \& Gregory, 2011; Griffin et al., 2013). Hence, learning intervention should be able to stimulate students' learning motivation. This is because Siti Fardaniah and Shamsuddin (2011) 
demonstrated that although motivation to learn can be the most influential factor, the classroom characteristic is the easier factor that can be manipulated to encourage academic performance.

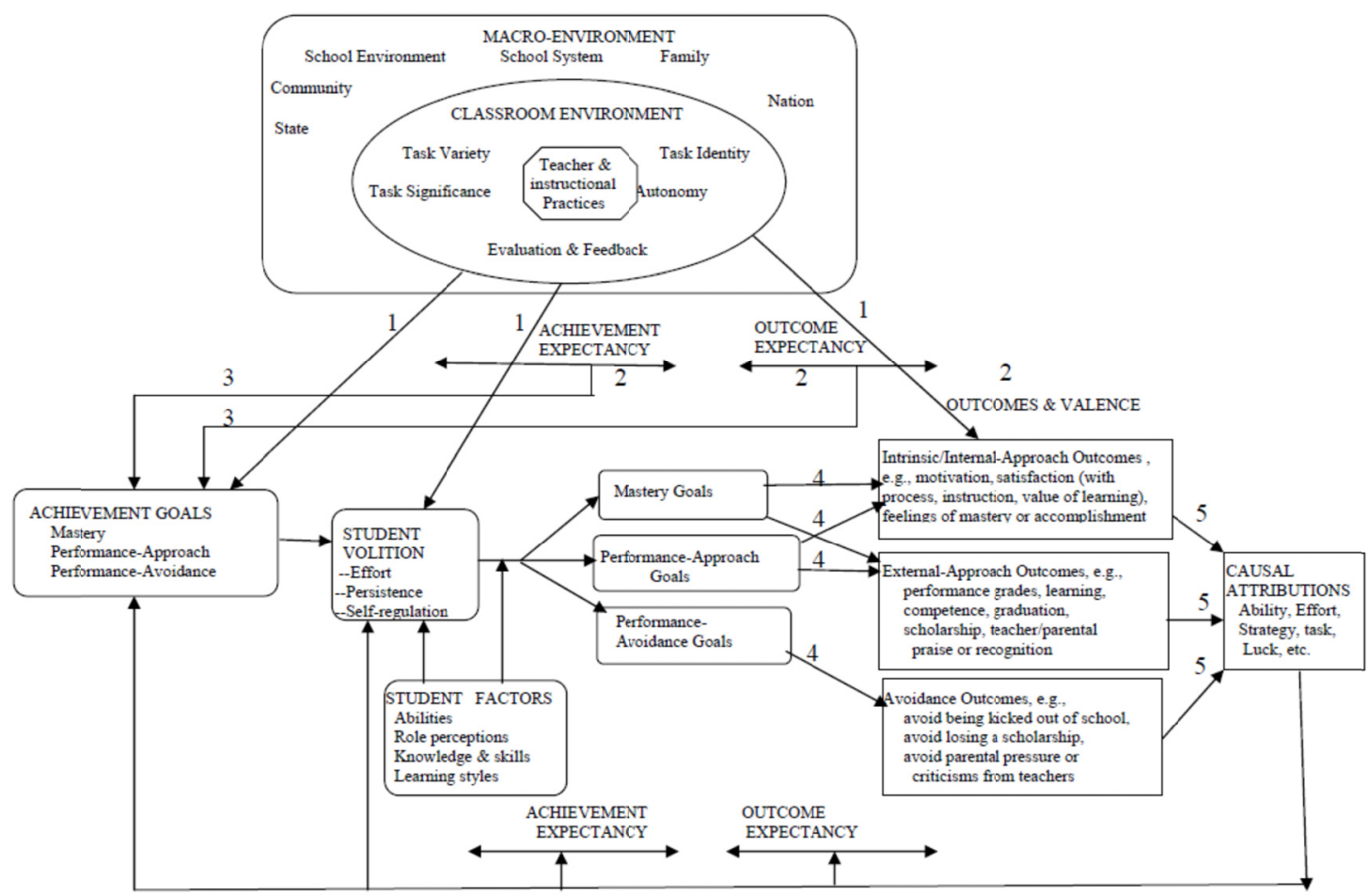

Figure 1. An integrated model of college student motivation Source: Debnath (2005, p. 170)

This highlights that classroom characteristics that can affect student's performance can be used as potential intervention to stimulate learning motivation. This is consistent with findings by Todres et al. (2012) that indicate classroom characteristic including engagement with learning, reflections on learning methods and experiences, and the application of learning to future practice as the most important factor related to academic achievement of the medical students in higher education using a qualitative research. In fact, Meyers and Nulty (2009) argue that classroom environment should be aligned together with students' assessment especially through the curriculum design.

\subsection{Classroom Characteristics as Potential Intervention in $T \& L$}

Some researchers have indicated the importance of classroom characteristic to improve students' academic achievement. For example, Patnam (2013) indicated that 'School Resources' or the classroom environment was the most significant factor related to student performance in math subject among school students using secondary data of TIMSS 2007, which covered 59 countries around the world, involving about 425,000 students. Additionally, Debnath (2005) argues that the classroom environment for college students should consist of five major structural elements including the instructional practices (e.g., task variety, task identity, task significance, autonomy, and evaluation and feedback) and depending on the teacher behaviour.

Further, using an intensive literature review and quantitative study, Halawah (2011) argues that the classroom characteristics for undergraduate students should involve lecturer quality, classroom management, and teaching method to improve their academic achievement. Hence, lecturer quality is defined as the positive attitudes towards students (Brewer \& Burgess, 2005; Halawah, 2011). Lammers and Smith (2008) find that it is the most important learning factor in the university classroom as ranked by students; this includes the lecturer/instructor's enthusiasm, followed by knowledge of subject matter, respectfulness, level of interest in subject matter, approachability, ability to notice/respond to questions, level of patience, speaking style, ability to anticipate student's difficulty in understanding new concepts, and the ability to have control over the classroom. This is consistent by Halawah's (2011) findings that indicated lecturer quality as the most important indicator for classroom characteristics especially to improve students' motivation and performance. 
Nevertheless, classroom management is referred to an organized classroom environment and culture (Brewer, DeJonge, \& Stout, 2001; Halawah, 2011). For example, classroom management should be open and positive atmosphere, allow lecture to be presented appropriately, and determine the course objective at the beginning of class (Halawah, 2011). Nonetheless, teaching method is referred to as a structured and variety of learning process (Brewer, DeJonge, \& Stout, 2001; Halawah, 2011). For example, the teaching method should help students to understand the lecture contents, give sufficient time for students to do their presentation, create cooperation among students, and use variety of teaching methods (Halawah, 2011). In fact, there are many efforts that can be made to diversify the teaching method. For example, Rassuli (2012) finds that reward, such as bonus mark can motivate students in classroom setting for the college students. Meanwhile, Worm and Buch (2014) find that competition among students can be an influential teaching method that can increase students' performance.

Taken together, classroom characteristic is seemed to be the easier factor to be manipulated in order to improve academic performance among university students as well as to plan an intervention to improve T\&L. In fact, Elander et al. (2010) find that intervention was very important because it can improve students' learning. Hence, it is hypothesized that:

Hypothesis 1:

Classroom characteristics comprising lecturer quality, classroom management, and teaching method have a significant effect on students' grade performance.

\subsection{The Importance of Motivation to Learn}

Motivation to learn is very important for academic performance among students either in school or university. Interestingly, students' motivation can be referred to many motivational theories, in which, the cognitive theories of motivation seem to be the most practical in measuring the motivation to learn. In addition, prior researchers find that factors affecting university students' academic performance can be grouped into individual, family, and classroom characteristic; in which, these factors can be potential for learning intervention.

Motivation to learn among undergraduates is very important, in which, Griffin et al. (2013) find that intrinsic motivation was the most influential factor for academic achievement among university students in USA. They find that the learning motivation explains $50 \%$ variance in academic achievement. In addition, Masahiro-Yoshida et al. (2008) find that university students with high learning motivation will complete difficult task to get better academic achievement although they were those in lower academic achiever at the beginning of class. This implies the effect of motivation to learn as mediator, as demonstrated by Crumpton and Gregory's (2011) study. Consistently, Mann (2003) investigates the use of type based learning style education to increase the development of academic skills and motivation in college students with academic difficulties among 80 students that were tested using instrument of Accelerating Towards Learning And Success (ATLAS). Findings indicate that the use of type based learning style education had no significant effect to increase the development of academic skills among college students with academic difficulties. However, motivation to learn had significant effect in improving the academic skills; this has demonstrated the effect of learning motivation as a mediator.

Nevertheless, Hudy (2006) finds that although students' motivation had a significant effect on CGPA among university students; however, the effect size is small. Hudy (2006) argues that there is a significant different between gender that probably affects this relationship; in which, girls were more motivated to learn. This implies that differences in group of students, such as different courses, years of study, races, gender, and programs can affect this relationship in resulting low relationship. This is consistent with Taylor-Sims's (2011) study that indicated university students' motivation only explains $20 \%$ variance in first-semester college grade point average. Additionally, Prager (2010) finds that the relationship between individual factors and students' performance was weak; in which, motivation can only explains $10 \%$ variance in the students' performance but other individual factors were lesser than the effect of motivation. Hence, variations in sample can affect the effect of motivation to learn as mediator.

On the other hand, there are many motivation theories that can be useful to explain students' motivation. Öztürk (2012) explains many contemporary motivation theories in educational psychology that can explain students' motivation; in which, Tollefson (2000) suggests that cognitive theories of motivation is the best theory of motivation to explain students' learning motivation. Meanwhile, using a quantitative study, Coleman (2006) finds that only the Goal-orientation Theory and Self-efficacy Theory were suitable to measure motivation to learn among university students. This is consistent with findings by Taylor-Sims (2011) that indicates only task value and self-efficacy were related to learning performance when these indicators were measured for students' 
motivation using Motivated Strategies for Learning Questionnaire (MLSQ). This implies that the Goal-orientation Theory and Self-Efficacy Theory of cognitive motivation are applied for students' motivation for the undergraduates.

On the other hand, prior researchers find that the same factors influencing students' academic achievement also affecting the learning motivation. For example, Teoh, Koob and Singh (2010) investigate factors that statistically explain the variation of motivation using a sample of mathematics students in a university; findings indicate that some influential factors were the relevant of learning, confidence, interest, and efforts. This has shown the significant effect of individual characteristic on learning motivation and performance. Meanwhile, other factors including family support only explain small percentage of variance in the motivation to learn and performance. In addition, Rugutt and Chemosit (2009) find that critical thinking skills, student-to-student relations, and student-faculty interaction were significant factors for student performance using a sample of 2,190 undergraduate students; in which, these factors explain $40.7 \%$ of variance in motivation. Additionally, Gopalan, Khojasteh and Cherikh (2012) find that the role of the teacher (lecturer) among university student can affect the motivation and learning styles of their students including encourage active participation, seek their opinions and provide ample opportunities for expressing their thoughts. These have shown the significant effect of classroom characteristic on learning motivation and performance.

Taken together, motivation to learn among university students is very important as mediating variable on the relationship between independent factors and students' academic performance. Hence, it is hypothesized that:

Hypothesis 2:

Motivation to learn mediates the relationship between classroom characteristics and students' grade performance.

\subsection{Research Framework}

Based on the literature review, a research framework is developed to achieve the research objective (see Figure 2). The research framework explains that motivation to learn mediates the relationship between classroom characteristic and the students' academic performance (students' grade). Students' grade is the dependent variable, motivation to learn is the mediator, and classroom characteristic is the independent variable. The classroom characteristic includes lecturer quality, teaching method, and classroom management. All variables have a positive relationship with each other.

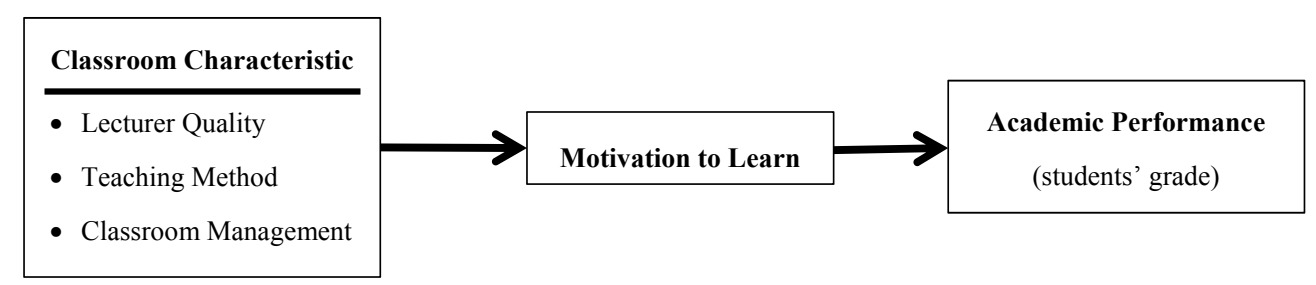

Figure 2. Research Framework

\section{Methodology}

This study used quantitative approach and survey study. In addition, census technique was applied to determine the sample in the study involving 173 samples from 233 undergraduate students of PPPPM (School of Psychology and Human Development), FSSK (Faculty of Social Sciences and Humanities), UKM (The National University of Malaysia) in 2013. From 233 students, only 196 were willing to get involved in this study; this demonstrates $84.12 \%$ of return rate. However, due to incomplete data and outliers only 173 samples were chosen. According to Kothari $(2004$, p. 14$)$, census is a technique used to determine sample size by collecting "...a complete enumeration of all items in the population". Meanwhile, Ranjit (2011, p. 164) stresses that "...information obtained from a census is likely to be more valid and reliable". Meanwhile, using G-Power analysis, the power (1- $\beta$ err prob) is 0.98 with 173 sample size demonstrating sufficient sample size for SEM-AMOS analysis.

Instrument used to collect data for motivation to learn was adapted from the Student Motivation Scale developed by Coleman (2006). In addition, instrument used to collect data for classroom characteristic was adapted from the questionnaire developed by Halawah (2011). These questionnaires were translated from English to Malay language using back-to-back translation technique as suggested by Andriesen (2008). Meanwhile, the student 
performance was collected using the grade that they achieved in any subject that they have taken previously. In the questionnaire, students were asked to remember only one subject that they have taken previously to answer the questionnaire. Additional information about the respondents including their race, religion, year of study, gender, age, program, and the name of course that they use to answer the questionnaire were also asked in the questionnaire.

Using quantitative approach, the relationship between classroom characteristic, motivation to learn, and student's grade were analysed with correlation, prediction, and mediation analysis. Therefore, SEM-AMOS and SPSS analysis were used to analyse the data. Using SPSS, reliability analysis, exploratory data analysis (EDA) and comparison between variations of respondents were analysed. Meanwhile, the SEM-AMOS analysis was used to analyse the correlation, prediction and mediation effect.

Using SPSS, the EDA was analysed using MLR. Findings have shown that there is no violation of multivariate analysis, such as linearity test, heteroscedasticity of errors, independent or errors, and with minimal cases of outliers. In addition, using SEM-AMOS analysis, the skew and kurtosis value have shown that data was normally distributed. In addition, the reliability analysis to measure each variable in this study was larger than 0.7 ; this demonstrate that the instrument was reliable (see Table 1).

Table 1. Reliability

\begin{tabular}{cccc}
\hline Item Number & Variable Measured & Total Item & Croanbach's Alpha \\
\hline B1-B20 & Motivation to learn & 18 & .862 \\
C1-C12 & Lecturer quality & 12 & .882 \\
C13-C24 & Teaching method & 12 & .910 \\
C25-C30 & Classroom management & 6 & .907 \\
\hline
\end{tabular}

\section{Findings and Discussion}

Findings indicate that motivation to learn had a significant full mediation effect on the relationship between classroom characteristic and student's grade. This has demonstrated the importance of motivation; in which, classroom characteristic would not have any effect on student's grade without the motivation to learn. In addition, findings have also revealed some characteristics of lecturer quality, teaching method, and classroom management that are potential for future learning intervention.

4.1 Characteristics of Lecturer Quality, Teaching Method, and Classroom Management Potential for T\&L Intervention

Classroom characteristic including lecturer quality, teaching method and classroom management was adapted from the instrument developed by Halawah (2011). Halawah (2011) developed the instrument for classroom characteristic using 30 items and have tested for the content validity and construct validity using EFA among 232 students in Al-Ain University at United Arab Emirates. He developed the instrument based on extensive literature review on factors of classroom climate that can motivate students' motivation to learn using three indicators including lecturer quality, teaching method and classroom climate.

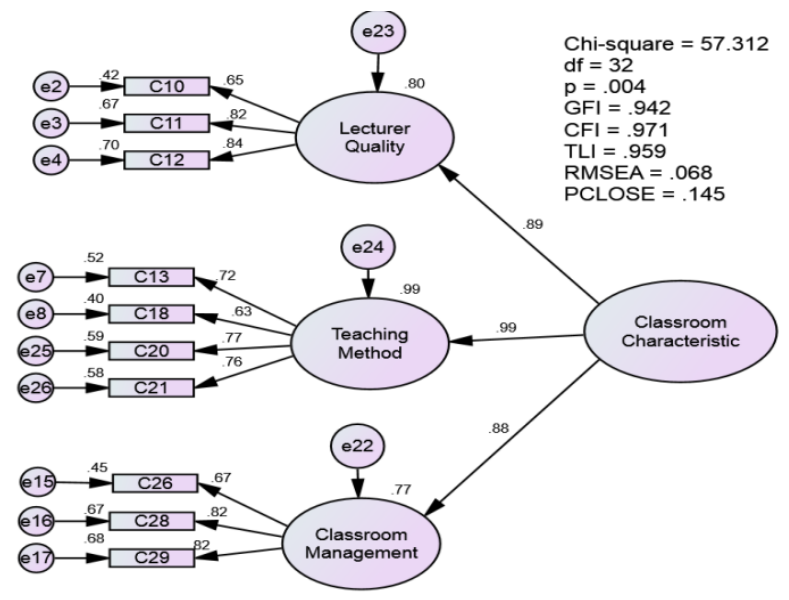

Figure 3. Structural model for classroom characteristic

Notes: All variances and regression weight are significant at 0.01 level (2-tailed) 
Based on SEM-AMOS (see Figure 3), there were three important criteria for lecturer quality (Item C10-C12), four important criteria for teaching method (Item C13, C18, C20-C21), and three important criteria for classroom management (Item C26, C28-C29). The structural model fit the data with; $x^{2}(2)=57.312$ with $p=0.004, x^{2} / \mathrm{df}=$ 1.95764 , GFI $=0.942, \mathrm{CFI}=0.971, \mathrm{TLI}=0.959$, and RMSEA $=0.068$ with PCLOSE $=0.145$. The structural model also shows that teaching method was the most important classroom characteristic $(\beta=.99, p=.001)$ followed by lecturer quality $(\beta=.89, p=.001)$ and classroom management $(\beta=.88, p=.001)$.

In conclusion, findings indicated that the teaching method should help students to understand the lecture contents, give sufficient time for students to do their presentation, create cooperation among students, and use variety of teaching methods. Meanwhile, a quality lecturer should remember their students (name/background), has a good relationship with students, and always be patient to them. Further, the classroom management should be open and positive atmosphere, allow lecture to be presented appropriately, and determine the course objective at the beginning of class.

\subsection{Mediation Effect of Motivation to Learn}

Motivation to learn was found to have a significant full mediation effect on the relationship between classroom characteristic and student's grade. In addition, classroom characteristic that comprise of lecturer quality, teaching method, and classroom management had a large effect on motivation to learn; meanwhile, motivation to learn had only a medium effect on student's grade. The unexpected result might be explained by the variation of respondents as shown by the one-way ANOVA analysis.

Table 2 shows the correlation, squared correlation, average variance extracted (AVE), and constructs reliability (CR) between variables in measurement model for variables involved in this research. The measurement model has met a model fit with; $x^{2}(2)=48.941$ with $p=0.003, x^{2} / \mathrm{df}=1.95764, \mathrm{GFI}=0.940, \mathrm{CFI}=0.969$, TLI $=0.955$, and RMSEA $=0.075$ with PCLOSE $=0.094$. In addition, all variables involved had sufficient construct validity as suggested by Hair et al. (2010). In addition the $\mathrm{CR}$ for each variable was greater than 0.7 indicating sufficient reliability; these formula was taken from Hair et al. (2010).

Table 2. Correlation, squared correlation, average variance extracted (AVE), and constructs reliability (CR) between variables

\begin{tabular}{cccccc}
\hline AVE & CR & & Student's Grade & Motivation to Learn & Classroom Characteristic \\
\hline- & - & Student's Grade & - & .41 & .24 \\
.576 & .870 & Motivation to Learn & .1681 & - & .53 \\
.707 & .879 & Classroom Characteristic & .0576 & .2809 & - \\
\hline
\end{tabular}

Notes: Values above the diagonal are correlations as produced by SEM. Values below the diagonal are squared correlation. All correlations are significant at .01 level (2-tailed)

Further, Figure 4 shows the structural model and Table 3 shows regression weight in the structural model. The structural model also fit the data as similar as the measurement model. However, only the effect of classroom characteristic on motivation to learn $(\beta=.53, p=.001)$ and the effect of motivation to learn on students grade $(\beta$ $=.40, p=.001)$ were significant at 0.05 level of significant. This demonstrates that classroom characteristic had a large effect on motivation to learn and can explain about $28 \%$ variance in motivation to learn. However, motivation to learn had a medium effect on student's grade $(\beta=.40)$ and can only explain $17 \%$ variance in the student's grade. The unexpected result might be explained by the variation of respondents; wherein, the one-way ANOVA analysis has shown that there were a significant difference between respondent in different year of study and different programs (see Table 4). These differences might have affected the strength effect of motivation to learn as mediator.

Furthermore, Figure 5 shows a direct model to determine the mediation effect of motivation to learn. The direct model shows that classroom characteristic had a significant effect on students' grade $(\beta=.24, p=.003)$ when the effect of motivation to learn was constrained; this indicates that the independent variable had a significant effect on dependent variable without the present of mediator. Hence, hypothesis 1 was fully supported indicating that classroom characteristics comprising lecturer quality, classroom management, and teaching method have a significant effect on students' grade performance.

Additionally, the structural model (Figure 4) shows that classroom characteristic had a significant effect on motivation to learn $(\beta=.53, p=.001)$ indicating that the independent variable had a significant effect on mediator. In addition, motivation to learn had a significant effect on students' grade $(\beta=.40, p=.001)$ indicating 
that the mediator had a significant effect on dependent variable. Nonetheless, classroom characteristic had no significant effect on students' grade $(\beta=0.03, p=.760)$ with the present of mediator. This has shown that there was a full mediation effect of motivation to learn on the relationship between classroom characteristic and students' grade at 0.05 level of significant. This is consistent with result by the percentile bias-corrected bootstrapping that shows a significant indirect effect of classroom characteristic on students' grade $(p=.01)$. Hence, without motivation to learn, classroom characteristic would not have any effect on the students' grade. Therefore, hypothesis 2 was fully supported indicating that motivation to learn mediated the relationship between classroom characteristics and students' grade performance.

Table 3. Regression weight in the structural model

\begin{tabular}{ccccc}
\hline \multicolumn{3}{c}{ Hypothesized Path } & Standardized Regression Weights Estimates $(\beta)$ & $p$ \\
\hline GRADE & $<--$ & Classroom Characteristic & .028 & .760 \\
GRADE & $<---$ & Motivation to learn & .397 & $* * *$ \\
Motivation to learn & $<---$ & Classroom Characteristic & .531 & $* * *$ \\
\hline
\end{tabular}

Notes: $\quad * * *$ significant at .001 (2-tailed)

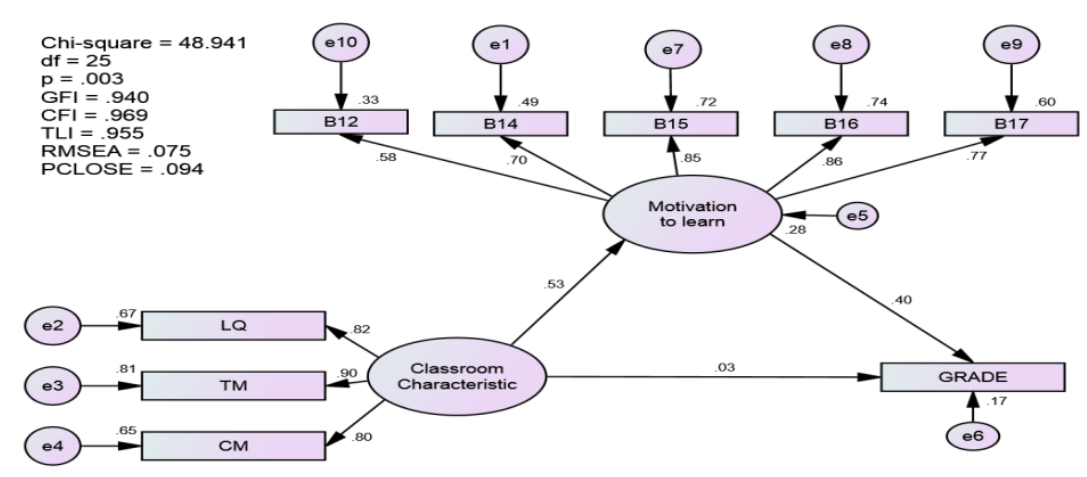

Figure 4. Structural model for SEM-AMOS analysis

Notes: All variances are significant at 0.01 level (2-tailed)

$\mathrm{LQ}=$ lecturer quality, $\mathrm{TM}=$ teaching method, $\mathrm{CM}=$ classroom management

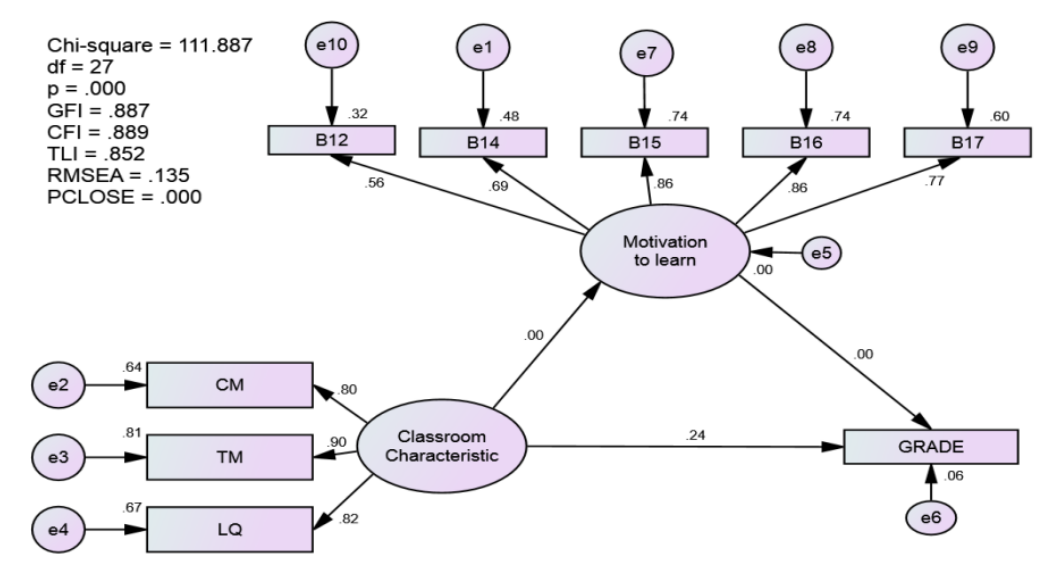

Figure 5. The direct model

Notes: Classroom characteristic has a significant effect on students' grade $(\beta=.24, p=.003)$ when the effect of classroom characteristic on motivation to learn and the effect of motivation to learn on students' grade were constrained.

$\mathrm{LQ}=$ lecturer quality, $\mathrm{TM}=$ teaching method, $\mathrm{CM}=$ classroom management 
Table 4. One-way ANOVA test to determine the differences of respondents' group

\begin{tabular}{cccc}
\hline Group Differences & $\mathrm{N}$ & $\mathrm{F}$ & Sig \\
\hline Races & 172 & 1.462 & .184 \\
Religion & 171 & 1.343 & .233 \\
Year of study & 170 & 2.238 & $.034^{*}$ \\
Gender & 170 & 1.000 & .427 \\
Programs & 172 & 2.147 & $.042^{*}$ \\
\hline
\end{tabular}

Notes: $\quad$ Dependent variable $=$ students' grade; ${ }^{*}$ significant at .05 (2-tailed)

Findings indicated that motivation to learn had a significant full mediation effect on the relationship between classroom characteristic and student's grade. This is consistent with findings by Crumpton and Gregory (2011) although their study was done among school students. This implies the importance of motivation to learn among students either in school or university. In addition, findings indicated that motivation to learn only had a medium effect on student's grade $(\beta=.40, p=.001)$ and can explain $17 \%$ variance in students' grade. This is consistent with findings by Taylor-Sims (2011) that finds the students' motivation only explain $20 \%$ variance in CGPA among university students. However, the effect of motivation to learn on students' grade can be much higher as demonstrated by Griffin et al.'s (2013) study if there is no significant difference between the respondents in term of years of study and programs taken. This is also demonstrated through a study by Hudy (2006) that indicates a small effect size between motivation and CGPA among university students because there was a significant different between genders.

In addition, classroom characteristic that comprise of lecturer quality, teaching method, and classroom management had a large effect on motivation to learn among the undergraduate students. This is consistent with studies by Halawah (2011) and Patnam (2013). Inconsistently, findings of the research indicated that the most important classroom characteristic was teaching method $(\beta=.90, p=.001)$, followed by lecturer quality $(\beta=.82$, $p=.001)$, and classroom management $(\beta=.80, p=.001)$. However, Halawah (2011) finds that the most important intervention was lecturer quality followed by teaching method, and classroom management; Lammers and Smith (2008) also find that lecturer quality as the most influential factor. The inconsistent findings might be explained by the different culture among respondents; in which, Jin (2013), and Chen (2007) and Cortazzi argue that the different culture among students can determine the different learning motivation for academic performance. Hence, for Malaysian culture, it is demonstrated that teaching method is the most important classroom characteristic that can be potential for learning intervention, followed by lecturer quality and classroom management among the undergraduates.

\section{Limitation and Recommendation}

There are some limitations and recommendations for the study. The study was done only in a department in a large public university in Malaysia; hence, there are limitations of sample selection and method of study. Additionally, it is recommended for educational practitioner to focus on some classroom characteristic as learning intervention to stimulate motivation to learn and students' performance for higher educational institution.

There is some limitation of the research. First, sample was taken only in a department in one public university (PPPPM, FSSK, UKM) although the organization was large; hence intensive comparison of variations in students cannot be analysed. Since findings indicated that variations of student can affect the strength effect between variables investigated, the comparison of these variations should be investigated in future research. Future researcher should replicate the research by using variety of students in terms of field of study/specialization, different faculties and universities, and sub-region location. Second, this research was done using quantitative and survey design. Hence, future researchers can consider using multiple methods of research, such as action research, experiment, longitudinal study, qualitative research, etc. For example, some researchers including Moghaddam (2007) and Norton et al. (2011) argue that action research is a suitable method in verifying intervention studies.

On the other hand, it is recommended for educational practitioner to focus on teaching method, followed by lecturer quality, and classroom management as learning intervention especially in Malaysia. Wang et al. (2013) argue that university students would change their learning style according to the classroom environment; hence, classroom intervention should be done to stimulate learning motivation and students' performance for higher educational institution. Therefore, the teaching method should help students to understand the lecture contents, 
give sufficient time for students to do their presentation, create cooperation among students, and use variety of teaching methods. Debnath (2005) explains that a good teaching method should also involve task variety, task identity, task significance, autonomy, and evaluation and feedback. In fact, other intervention can be organized to stimulate motivation to learn and student's performance, such as giving rewards for high achiever (Rassuli, 2012), and organizing competition among students (Worm \& Buch, 2014).

Furthermore, the classroom management should be open and positive atmosphere, allow lecture to be presented appropriately, and determine the course objective at the beginning of class. Meanwhile, Todres et al. (2012) suggest that classroom management should engage students, involve reflections on learning methods and experiences, and apply learning to future practice. In addition, a good quality of lecturer should remember their students (name/background), has a good relationship with students, and always be patient to them. This is consistent with Lammers and Smith (2008) findings that explains students prefer a lecturer/instructor with high enthusiasm, followed by knowledge of subject matter, respectfulness, level of interest in subject matter, approachability, ability to notice/respond to questions, level of patience, speaking style, ability to anticipate student's difficulty in understanding new concepts, and the ability to have control over the classroom.

\section{Conclusion}

In conclusion, the purpose of this research was to determine the mediation effect of motivation to learn on the relationship between classroom characteristic and students' grade performance among university students; these classroom characteristic can be used as learning intervention. Findings indicated that motivation to learn had a significant full mediation effect on the relationship between classroom characteristic and students' grade performance. Motivation to learn was found to have medium effect on students' grade and can explain 17\% variance in students' grade. Meanwhile, classroom characteristic was found to affect motivation to learn with large effect size and can explain $40 \%$ variance in motivation to learn. In addition, variations in students (including variations in the year of study and programs taken) can affect the relationship between motivation to learn and students' performance; hence it should be investigated in future studies. Additionally, the characteristic of classroom that can be potential for learning intervention are appropriate teaching method, followed by lecturer quality and classroom management.

\section{Acknowledgments}

Special thanks to Universiti Kebangsaan Malaysia that supported the research under Strategic Action Research Grant (PTS-2013-047).

\section{References}

Andriesen, S. (2008). Benefiting from back translations. International Clinical Trials, Summer, 16-20.

Aziz, S. F. A., \& Ahmad, S. (2011). Stimulating training motivation using the right training characteristic. Industrial and Commercial Training, 43(1), 53-61. http://dx.doi.org/10.1108/00197851111098171

Chen, J. J. (2007). Immigrant status, academic achievement, and academic outcomes. In P. R. Zelick (Ed.), Issues in the Psychology of Motivation. USA: Nova Publishers.

Coleman, M. A. (2006). Construct validity evidence based on internal structure: exploring and comparing the use of RASCH measurement modelling and factor analysis with a measure of student motivation (Doctoral dissertation). Retrieved from http://search.proquest.com/docview/304920086/fulltextPDF/1EB8C6A14B91 4297PQ/1?accountid=41453.

Cortazzi, M., \& Jin, L. (2013). Researching cultures of learning: International perspectives on language learning and education. http://dx.doi.org/10.1057/9781137296344

Crumpton, H. E., \& Gregory, A. (2011). "I'm not learning": The role of academic relevancy for Low-achieving students. The Journal of Educational Research, 104, 42-53. http://dx.doi.org/10.1080/00220670903567398

Debnath, S. C. (2005). College student motivation: An interdisciplinary approach to an integrated learning systems model. Journal of Behavioral and Applied Management, 168-188.

Elander, J., Pittam, G., Lusher, J., Fox, P., \& Payne, N. (2010). Evaluation of an intervention to help students avoid unintentional plagiarism by improving their authorial identity. Assessment \& Evaluation in Higher Education, 35(2), 157-171. http://dx.doi.org/10.1080/02602930802687745

Gopalan, S., Khojasteh, M., \& Cherikh, M. (2010). The impact of faculty teaching styles on student motivation and learning: Results from an exploratory study of B-school students from India (Vol. 10). New Orlean: Proceedings of the Academy for Studies in International Business. 
Griffin, R., MacKewn, A., Moser, E., \& VanVuren, K. W. (2013). Learning skills and motivation: Correlates to superior academic performance. Business Education \& Accreditation, 5(1).

Hair, J. F. J., Black, W. C., Babin, B. J., Anderson, R. E., \& Tatham, R. L. (2010). Multivariate data analysis (7th ed.). Upper Saddle River, New Jersey: Pearson Prentice Hall.

Halawah, I. (2011). Factors influencing college students' motivation to learn from students' perspective. Education, 132(2), 379-389.

Hudy, G. T. (2006). An analysis of motivational factors related to academic success and persistence for university students (Doctoral dissertation). Retrieved from http://search.proquest.com/docview/304951305/ fulltextPDF/65FD50D79F9247BBPQ/1?accountid=41453

JPT. (2014). Jabatan Pendidikan Tinggi Malaysia (Department of Higher Education Malaysia). Retrieved February 22, 2014, from http://jpt.mohe.gov.my/

Kerssen-Griep, J. D. (1997). Teacher communication and student motivation to learn: Competence as classroom facework (Doctoral dissertation). Retrieved from http://search.proquest.com/docview/304374079/fulltext PDF/603F9FD9C90F4704PQ/1?accountid $=41453$

Kothari, C. R. (2004). Research methodology: Methods and techniques. USA: New Age International.

Knowles, M. S. (1980). The modern practice of adult education: From pedagogy to andragogy. Englewood Cliffs: Prentice Hall/Cambridge.

KPM. (2014). Kementerian Pendidikan Malaysia (Ministry of Education Malaysia). Retrieved February 22, 2014, from http://www.moe.gov.my/

Kumar, R. (2011). Research methodology: A step-by-step guide for beginners (3rd ed.). London: SAGE Publications Ltd.

Lammers, W. J., \& Smith, S. M. (2008). Learning factors in the university classroom: Faculty and student perspectives. Teaching of Psychology, 35, 61-70. http://dx.doi.org/10.1080/00986280802004586

Lewin, K. (1946). Action research and minority problems in Action Research, Wikipedia (2013). Retrieved April 5, 2013, from http://en.wikipedia.org/wiki/Action_research

Mann, W. C. (2003). The use of type based learning style education to increase the development of academic skills and motivation in college students with academic difficulties (Doctoral dissertation). Retrieved from http://search.proquest.com/pagepdf/305225577/fulltextPDF/998BCF4EC229483EPQ/1?accountid=41453

Meyers, N. M., \& Nulty, D. D. (2009). How to use (five) curriculum design principles to align authentic learning environments, assessment, students' approaches to thinking and learning outcomes. Assessment \& Evaluation in Higher Education, 34(5), 565-577. http://dx.doi.org/10.1080/02602930802226502

Moghaddam, A. (2007). Action research: A spiral inquiry for valid and useful knowledge. Alberta Journal of Educational Research, 53(2), 228-239.

Montgomery, M. S. (1998). The development of the scale of academic motivation (Doctoral dissertation). Available from ProQuest Dissertation \& Theses: Full Text (UMI No. 9921818).

Norton, C. L., Russell, A., Wisner, B., \& Uriarte, J. (2011). Reflective teaching in social work education: Findings from a participatory action research study. Social Work Education, 30(4), 392-407. http://dx.doi.org/10.1080/02615479.2010.500658

Osman, M., Zain, A., Muhammad, T. J., \& Ibrahim, A. B. (2013). Factors influencing students' decisions in choosing private institutions of higher education in Malaysia: A structural equation modelling approach. Asian Academy of Management Journal, 18(1), 75-90.

Öztürk, E. Ö. (2012). Contemporary motivation theories in educational psychology and language learning: An overview. The International Journal of Social Sciences, 3(1), 33-46.

Patnam, V. S. (2013). Factors related to student achievement in mathematics and comparison of the U.S. with other countries: A study based on TIMSS 2007 Report (Doctoral dissertation). Retrieved from $\mathrm{http} / /$ search.proquest.com/docview/1434876028/fulltextPDF/6ED8D44B80C14F41PQ/1?accountid=41453

Prager, E. K. (2010). An evaluation of factors affecting student performance on broad measures of student learning (Doctoral dissertation). Retrieved from http://search.proquest.com/docview/897100683/fulltext $\mathrm{PDF} / 8 \mathrm{ED} 2972 \mathrm{D} 37 \mathrm{CF} 42 \mathrm{~F} 6 \mathrm{PQ} / 1$ ? accountid=41453 
Rahim, N. A. (2005). Impact of learner involvement in materials and task design on motivation in learners of English: An investigation focusing on storyboard software at University Putra Malaysia (Unpublished doctoral dissertation). University Putra Malaysia at Serdang, Selangor, Malaysia.

Rahman, F., Jumani, N. B., \& Basit, A. (2010). Motivating and de-motivating factors among learners. International Journal of Academic Research, 2(1).

Rassuli, A. (2012). Engagement in classroom learning: creating temporal participation incentives for extrinsically motivated students through bonus credits. Journal of Education for Business, 87, 86-93. http://dx.doi.org/10.1080/08832323.2011.570808

Rosenthal, J. L. (2012). Motives and methods: Motivation, learning approaches, and academic achievement of students during first year transition to medical school (Doctoral dissertation). Retrieved from http://search.proquest.com/docview/1151827934/fulltextPDF/38A350EE15C443ECPQ/1?accountid=41453

Rugutt, J., \& Chemosit, C. C. (2009). What motivates students to learn? Contribution of student to-student relations, student-faculty interaction and critical thinking skills. Educational Research Quarterly, 32(3), $16-28$.

Shea, G. (2006). A model of individual and family factors related to achievement (Masters dissertation). Retrieved from http://search.proquest.com/docview/305358755/fulltextPDF/4698282B91D44E5BPQ/ 1? accountid $=41453$

Taylor-Sims, M. A. (2011). Differences in motivation and cognitive learning strategy use from high school to college and impact on first-semester college grade point average (Doctoral dissertation). Retrieved from http://search.proquest.com/pagepdf/880559582/fulltextPDF/625C94AEC6DA4D1EPQ/1?accountid=41453

Teoh, S. H., Koob, A. C., \& Singh, P. (2010). Extracting factors for students' motivation in studying mathematics. International Journal of Mathematical Education in Science and Technology, 41(6), 711-724. http://dx.doi.org/10.1080/00207391003675190

Todres, M., Tsimtsiou, Z., Sidhu, K., Stephenson, A., \& Jones, R. (2012). Medical students' perceptions of the factors influencing their academic performance: An exploratory interview study with high-achieving and re-sitting medical students. Medical Teacher, 34, 325-331. http://dx.doi.org/10.3109/0142159X.2012. 668626

Tollefson, N. (2000). Classroom applications of cognitive theories of motivation. Educational Psychology Review, 12(1), 63-83. http://dx.doi.org/10.1023/A:1009085017100

Wang, X., Su, Y., Cheung, S., Wong, E., \& Kwong, T. (2013). An exploration of Biggs' constructive alignment in course design and its impact on students' learning approaches. Assessment \& Evaluation in Higher Education, 38(4), 477-491. http://dx.doi.org/10.1080/02602938.2012.658018

Worm, B. S., \& Buch, S. V. (2014). Does competition work as a motivating factor in e-learning? A randomized controlled trial. PLOS ONE, 9(1). http://dx.doi.org/10.1371/journal.pone.0085434

Yahaya, N., Yahaya, A., Ramli, J., Hashim, S., \& Zakariya, Z. (2010). The effects of extrinsic motivational factors in learning among students in secondary school in Negeri Sembilan. International Journal of Psychological Studies, 2(1). http://dx.doi.org/10.5539/ijps.v2n1p128

Yoshida, M., Tanaka, M., Mizuno, K., Ishii, A., Nozaki, K., Urakawa, A., ... Watanabe, Y. (2008). Factors influencing the academic motivation of individual college students. International Journal of Neuroscience, 118, 1400-1411. http://dx.doi.org/10.1080/00207450701242982

\section{Copyrights}

Copyright for this article is retained by the author(s), with first publication rights granted to the journal.

This is an open-access article distributed under the terms and conditions of the Creative Commons Attribution license (http://creativecommons.org/licenses/by/3.0/). 